The knowledge of the atomic weight of silver is, as Prof. Brauner says, of such importance, that we have begun a new series of experiments to investigate the volatility and condensibility of silver.

H. B. BAKER.

H. L. RILEY.

Imperial College of Science, London, S.W.7.

\section{A New Method of Measuring the Absolute Surface Area of a Metallic Catalyst.}

IN a previous communication (NATURE, vol. 118, p. $730 ; 1926)$ it was shown that simultaneous measurements of the electrical conductivity, and the thickness of the oxide layer on a film of metallic copper supported on china-clay rods, enabled the fractional decrease in surface area on sintering to be evaluated.

The thickness of the oxide film was measured by observation of the surface colour. These results give directly the equivalent air thickness of the oxide film, but to convert them into absolute measure the refractive index of the film must also be known. The mineral cuprite, cuprous oxide, has a refractive index of 2.85 and is cubic; whereas cupric oxide, occurring in the mineral kingdom as tenorite, is anorthic, having values of the refractive index of 2.63 for red light, and $3 \cdot 18$ for blue. Cuprite is translucent, having a red colour ; tenorite is more opaque, occurring in scaly black crystals.

The colours shown by the oxide films are so marked that it is evident that in very thin films the absorption is almost negligible in amount. Since the oxide film is of higher refractive index than the air above it, the dispersion will tend to exaggerate the colours shown by films of a given thickness. The film is backed by metallic copper, and it is assumed that the path difference is caused by the passage of the light from the top of the film to the reflecting interface at the bottom and back again. With substances of such high refractive indices, the light in the film will be practically normal to the film in spite of the varying angles of incidence.

Let $S=$ the surface area of the metal forming $M$ grams of oxide spread over the china. clay support ;

$C=$ the electrical conductivity of the film ;

$q=$ equivalent air thickness of the oxide film ;

$\mu=$ refractive index of the oxide;

$\rho=$ density of the oxide;

$k_{c}=$ initiai value of the constant in the parabolic law for the fall in conductivity;

$k_{q}=$ initial value for the equivalent air thickness. Then the rate of formation of the oxide as a fraction of the total oxide possible

$$
\frac{\rho \cdot S}{M \cdot \mu} \cdot \frac{d q}{d t}
$$

is equal to the rate of disappearance of the metal, expressed similarly, i.e.

Hence we have

$$
\frac{1}{C} \cdot \frac{d C}{d t}
$$

$$
\frac{S}{M}=\frac{d C / d t . \mu}{d q / d t . C \cdot \rho}=\frac{\mu}{\rho \cdot C} \sqrt{\overline{k_{c}}} .
$$

For an activated copper film the following values were found, $k_{c}$ and $k_{q}$ being measured at $210^{\circ} \mathrm{C}$. :

$$
\begin{aligned}
k_{c}=1.52 \times 10^{-2} ; k_{q} & =2.50 \times 10^{-10} ; \mu=2.85 \text { (mean); } \\
c & =0.64 ; \rho=6.3 .
\end{aligned}
$$

Therefore $S / M=5500$ sq. cm. per gram of metallic oxide formed.

$=6900 \mathrm{sq}$. cm. per gram of film.
The area of the supporting china-clay rods for each gram of metallic film was $3200 \mathrm{sq}$. cm.

It is now possible to complete the comparison of the surface activity of pure electrolytic copper with that of activated reduced copper (Proc. Roy. Soc., A, vol. 110 , p. $285 ; 1926) .2000 \mathrm{sq}$. cm. of electrolytic copper had an activity that was imperceptible at $370^{\circ} \mathrm{C}$., whereas the activity of about $70 \mathrm{sq} . \mathrm{cm}$. of reduced copper was easily detected at $200^{\circ} \mathrm{C}$. From the temperature coefficient of the reaction the activity of $540,000 \mathrm{sq}$. cm. of electrolytic copper would have been imperceptible at $200^{\circ}$ C.; hence reduced copper has an activity that is at least 8000 times greater than that of electrolytic copper.

The activity of the smooth surface is very small indeed when compared with the reduced product.

These results, while showing very clearly the order of magnitude of the surface presented by reduced copper, cannot yet be regarded as accurate determinations until the growth of the oxide film has been studied by spectrometric methods. This research is now proceeding.

St. John's College,

$$
\text { Cambridge. }
$$

\section{Spectrographic Observations of the Second} Green Line of the Auroral Spectrum.

Is previous papers on the origin of the auroral spectrum, and recently in a letter to NATURE of Dec. 4, 1926, I have directed attention to the existence of a second green line lying in the region of about $\lambda 5230$, which should correspond to the line, or rather group of lines, $\mathrm{N}_{2}$, of the spectrum from solid nitrogen.

As stated in my letter to NATURE, this second auroral line is usually extremely faint and has only occasionally been observed with spectroscopes; in consequence, various observers have found values of the wave-length which differ within fairly wide limits.

On account of the faintness of the line, and also of the fact that the usual photographic plates have a minimum of sensitiveness in this region, I was not able during the early years of my work to obtain this line on my plates.

On a spectrogram made last autumn, however, on a panchromatic plate, I obtained for the first time, after an exposure of forty northern-light hours, this second line; but it was too faint for accurate measurements. The wave-length obtained was 5223 .

After this spectrogram had been taken I was able to obtain a sensitiser which gave the plates a high sensitivity in the region wanted. The first exposure with this plate was made in a small spectrograph with fairly high light power and a broad slit. It was exposed at the Geophysical Institute of Troms $\phi$ for fifteen effective northern-light hours. On this spectrogram, which gave the ordinary auroral lines much over-exposed, I also now obtained this second green line very well marked on the plate.

The accompanying reproduction (Fig. 1) shows the strong green auroral line marked by $a$, the second green line by $b$, and the strongest lines of the negative band spectrum by $c, d, e$.

It will be noticed first of all that the second green line is not sharp; although much weaker than the other lines, it covers a greater part of the spectrum. Measurements showed the breadth of the second green line to be $0.22 \mathrm{~mm}$., while that of the other lines, although more strongly exposed, was only $0.15 \mathrm{~mm}$

From this we can conclude that what is called the second green line is not a single line, but consists of a group of lines.

As stated in my previous letter to NATURE, this

No. 2992, VoL. 119] 